\title{
Conflitos ambientais no litoral norte do Paraná: um mapeamento preliminar
}

\section{Environmental conflicts in the north coast of Paraná: a preliminary mapping}

\author{
Ariane Maria Basilio Pigosso ${ }^{1}$ \\ Jandaira dos Santos Moscal ${ }^{2}$ \\ Jackson Goldbach ${ }^{3}$
}

\begin{abstract}
Resumo
Os conflitos ambientais, que resultam da coexistência de distintas práticas de apropriação social e cultural do mundo material, não deixariam de ocorrer no litoral norte do Paraná, recoberto por unidades de conservação e habitado por caiçaras, quilombolas, pescadores, indígenas. O presente trabalho relaciona, com base em levantamento criterioso de dados secundários, os conflitos que ocorrem na região, a fim de estabelecer um cenário que possa subsidiar ações de pesquisa e gestão. Foram constatados e mapeados oito conflitos que ocorrem em cerca de 30 das 74 comunidades da área de estudo.
\end{abstract}

Palavras-chave: Litoral do Paraná. Unidades de Conservação. Populações Tradicionais.

\begin{abstract}
Environmental conflicts, which result from the coexistence of different practices of social and cultural appropriation of the material world, would not cease to occur on the northern coast of Paraná, covered by protected areas and inhabited by "caiçaras", "quilombolas", fishermen and indigenous. The present work describes, based on secondary data gathering, the conflicts that occur in the region, in order to establish a scenario that can support research and management actions. Eight conflicts that occurred in about 30 communities of the 74 of the study area were found and mapped.
\end{abstract}

Keywords: Coast of Paraná state. Protected areas. Traditional populations.

\section{Introdução}

Composto pelos municípios de Guaraqueçaba, Antonina, Morretes, Paranaguá, Pontal do Paraná, Matinhos e Guaratuba, o litoral do Paraná apresenta uma vasta riqueza natural e cultural. Juntamente com uma parcela do litoral sul do estado de São Paulo, abriga o maior remanescente contínuo de Mata Atlântica, declarada Reserva da Biosfera pela UNESCO, considerada de extrema importância biológica pela Portaria $\mathrm{n}^{0}$ 009, de 2007, do Ministério do Meio Ambiente, e cuja

\footnotetext{
1 Doutoranda do Programa de Pós-Graduação em Geografia da Universidade Federal do Paraná. E-mail: ariane.pigosso@gmail.com

${ }^{2}$ Licencianda em Geografia pelo Centro Universitário Uninter. E-mail: jandamoscal@ gmail.com

${ }^{3}$ Graduando em Geografia pela Universidade Federal do Paraná. E-mail: jacksongoldbach@ gmail.com
} 
vegetação é protegida pela Lei n ${ }^{\circ} 11.428$, de 2006, a Lei da Mata Atlântica. Essas condições fizeram com que fossem criadas diversas áreas de conservação na região. Atualmente, 29\% do território do litoral paranaense é coberto por Unidades de Conservação de proteção integral e 53\% por de uso sustentável, num total de 14 unidades federais, 20 estaduais e 10 municipais (PAULA et al., no prelo).

Habitam a região populações caiçaras, indígenas e quilombolas, com seus usos relacionados, sendo a diversidade cultural humana reconhecida por alguns autores como um componente da biodiversidade. Segundo Araújo (2007) e Schmink et al. (1992), essas comunidades têm uma relação de dependência com os recursos naturais, o que faz com que a existência de ambos seja indissociável.

O desenvolvimento do presente estudo decorre do Plano de Trabalho "Ações de Suporte e Apoio Técnico ao Planejamento e Gestão das Unidades de Conservação Federais do Litoral Norte do Estado do Paraná", desenhado no âmbito do termo de cooperação técnica entre o Instituto Chico Mendes para Conservação da Biodiversidade (ICMBio) e a Universidade Federal do Paraná (UFPR), que visa à elaboração de ferramentas de planejamento e gestão ambiental do território para subsidiar a atuação dos analistas ambientais e conselheiros das UC no litoral norte do estado do Paraná (Figura 1), e que estão vinculadas ao ICMBio: 1- Área de Proteção Ambiental (APA) de Guaraqueçaba; 2Reserva Biológica (REBIO) Bom Jesus; 3- Estação Ecológica (ESEC) de Guaraqueçaba; e 4 - Parque Nacional de Superagüi (PNS). Esse termo de cooperação técnica foi firmado em 2014 e após renovação no final de 2017 será válido até agosto de 2019. 


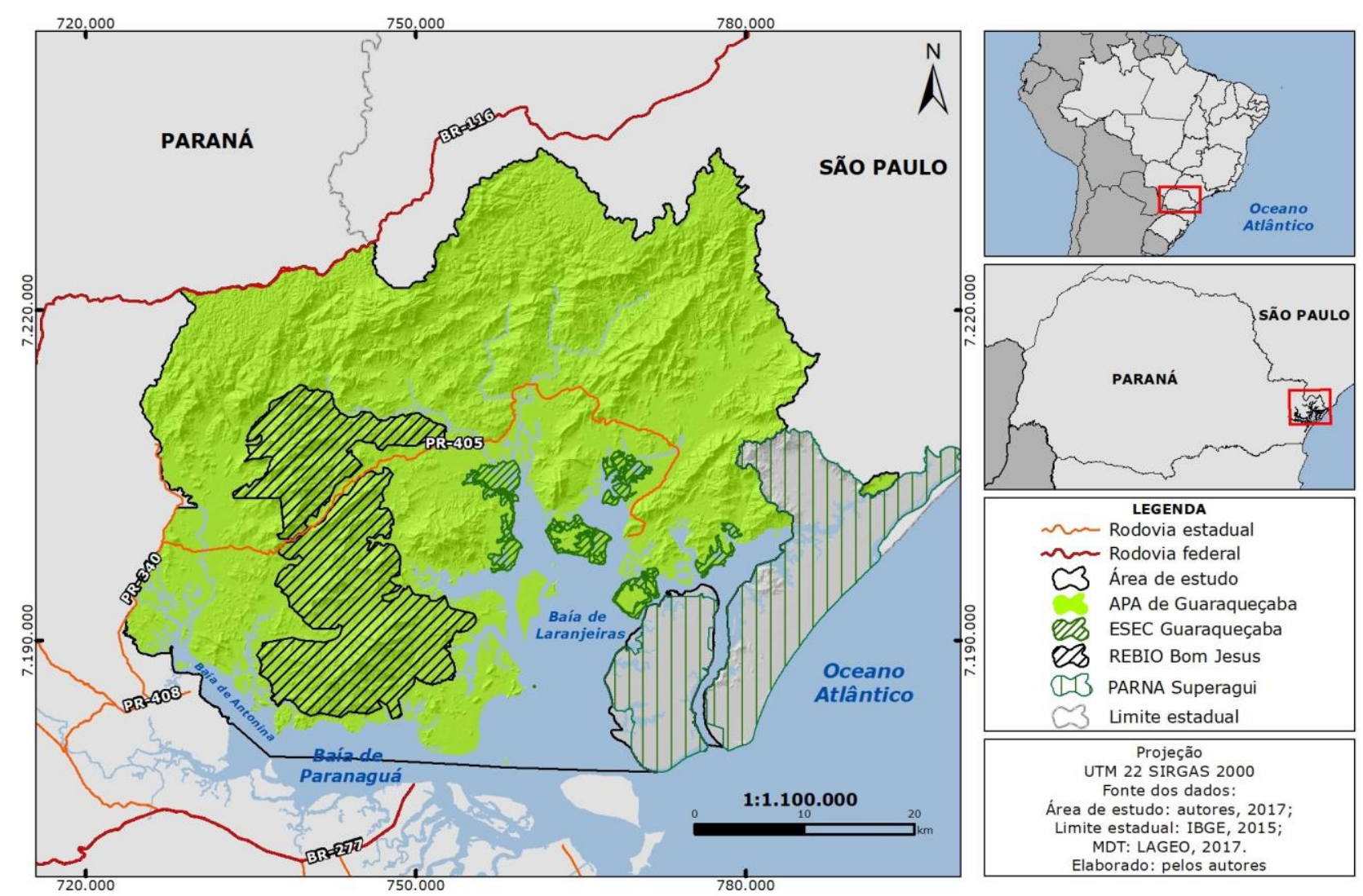

FIGURA 1 - MAPA DE LOCALIZAÇÃO DAS UNIDADES DE CONSERVAÇÃO E ÁREA DE ESTUDO FONTE: Os Autores.

Dentro da proposta de elaboração do Diagnóstico de Subsídio aos Planos de Manejo da APA de Guaraqueçaba, ESEC de Guaraqueçaba e REBIO Bom Jesus (PAULA et al., 2016), diversos planos de trabalho foram desenhados de acordo com as demandas levantadas junto ao ICMBio, dos quais um objetivou a apresentação de um panorama inicial dos conflitos ambientais que se passam na área das unidades supramencionadas e que serve de base para o presente artigo.

Um dos aspectos de grande relevância na gestão e manutenção das UCs tem sido a relação com as populações humanas que dividem o território com essas áreas protegidas. No contexto de discussão da relação UCs e populações humanas, despontam os conflitos ambientais. Na concepção de Little (2001), os conflitos socioambientais ocorrem mediante embates entre grupos sociais, com modos diferentes de se inter-relacionar com o ambiente social e natural, surgindo das interações ecológicas entre os diferentes atores sociais e o meio biofísico.

Dentro da perspectiva da cooperação técnica, o diagnóstico baseou-se, predominantemente, em dados secundários. A pesquisa de referencial foi ampla, envolvendo não só publicações acadêmicas, mas também sites institucionais, blogs de moradores locais e documentos de procedimentos administrativos do Ministério Público do Paraná. 
Os dados coletados em campo foram importantes para o reconhecimento da região e da aproximação dos pesquisadores com as realidades vivenciadas pelos moradores. Apesar da curta duração, foi possível o diálogo com os gestores das UCs, o conhecimento acerca das Organizações Não Governamentais (ONGs) atuantes na AE e interlocução com representantes dos camponeses do Acampamento José Lutzenberger; pescadores de Almeida e Medeiros de Baixo e quilombolas de Batuva e Rio Verde.

Como metodologia para a coleta de informações utilizou-se a pesquisa participante que, conforme Thiollent (2002) é, em alguns casos, um tipo de pesquisa baseado em uma metodologia de observação participante, na qual os pesquisadores estabelecem relações comunicativas com pessoas ou grupos da situação investigada. Foi utilizada a entrevista semiestruturada, que consiste em um roteiro pré-estabelecido de perguntas que apresentam certa flexibilidade durante o momento da entrevista, possibilitando um contato mais íntimo entre o entrevistador e o entrevistado, favorecendo assim a exploração de seus saberes (LAVILLE; DIONNE, 1999).

As perguntas se basearam em itens relativos ao histórico de uso e ocupação da área, atividades produtivas desenvolvidas pelos moradores e relações destes com a conservação da natureza. $\mathrm{O}$ questionário não apresentava respostas fechadas, as quais deveriam ser escolhidas pelos entrevistados, que tiveram liberdade para discorrer sobre o que lhes era perguntando, fazendo suas próprias ponderações sobre o que era, para eles, verdadeiro, e/ ou importante de ser dito, detalhando e levando o tempo que julgavam necessário para discorrer sobre os assuntos.

Foram levantados oito conflitos ambientais na $\mathrm{AE}$, os quais estão alocados conforme a tipologia dos conflitos socioambientais proposta por Little (2001): (1) os conflitos em torno do controle sobre os recursos naturais; e (2) os conflitos em torno dos impactos ambientais e sociais gerados pela ação humana e natural. Embora o autor apresente uma terceira proposição - (3) os conflitos em torno do uso dos conhecimentos -, nenhum dos conflitos ambientais levantados na AE foi encaixado nessa linha.

O presente artigo, através de descrição e tabelas sínteses, apresenta primeiramente os conflitos em decorrência dos impactos ambientais e sociais e na sequência traz a exposição dos conflitos pelo controle dos recursos naturais comuns. Por fim, apresenta um mapa com a espacialização dos conflitos levantados na AE e breves observações acerca dos desdobramentos desses conflitos. 


\section{Conflitos em torno dos impactos ambientais e sociais}

Há conflitos provenientes dos impactos negativos das ações humanas nos meios biofísicos, tais como contaminação de ambientes, esgotamento dos recursos naturais e degradação dos ecossistemas, com consequências na saúde humana e dos ambientes (LITTLE, 2001). Essas situações ainda podem ser frequentemente caracterizadas por uma distribuição desigual dos impactos positivos e negativos, a injustiça ambiental, quando aqueles que recebem as benesses de determinada intervenção não sofrem com os impactos negativos, enquanto que os que sofrem não se beneficiam com os efeitos positivos (ACSELRAD, 2004; ZHOURI; LASCHEFSKI, 2010).

$\mathrm{Na}$ comunidade de Cachoeira, agricultores familiares lidam com enchentes e desmoronamentos em decorrência do processo de assoreamento do rio Cachoeira, hipótese reforçada por Paula (2010), que levou o Ministério Público do Paraná (MPPR) a instaurar um Processo Administrativo (PA), por representação da ADEMADAN, com o objetivo de assegurar medidas compensatórias condizentes com os impactos não mitigáveis e a participação da sociedade civil no processo de renovação da licença ambiental da Usina Hidrelétrica Governador Parigot de Souza (MPPR, 2013). O caso consiste em exemplo de impacto negativo que gerou conflito, assim como descrito por Acselrad (2004) e ainda poderá gerar outros, uma vez que o processo de assoreamento ainda contribui para a diminuição de áreas pesqueiras.

TABELA 1 - POPULAÇÃO LOCAL E UHGPS

\begin{tabular}{l|l}
\hline $\begin{array}{l}\text { População } \\
\text { atingida }\end{array}$ & Agricultores familiares. \\
\hline Comunidade(s) & Cachoeira. \\
\hline Tensões & $\begin{array}{l}\text { Enchentes e desmoronamentos em propriedades da comunidade em decorrência do processo de } \\
\text { desassoreamento do rio Cachoeira, diminuição de áreas pesqueiras. }\end{array}$ \\
\hline $\begin{array}{l}\text { Impactos } \\
\text { ambientais }\end{array}$ & Assoreamento do rio Cachoeira, diminuição da biodiversidade. \\
\hline Referências & PA MPPR 0006.13.000217-0. \\
\hline
\end{tabular}

FONTE: adaptado de PAULA et al. (2016).

Com a inauguração em 1979 da Rodovia PR 405, que liga os municípios de Antonina e Guaraqueçaba, muitas famílias passaram a morar em suas proximidades, até mesmo às margens, tendo em muitos casos abandonado as residências antigas para reconstruírem suas relações no novo contexto de "progresso". O abandono da rota fluvial para transporte, escoamento de suas produções 
e demais necessidades não tardou. Com as condições precárias da estrada, os pedidos por melhorias se tornaram frequentes (CAMPOS; KOMARCHESKI; SULZBACH, 2013).

Em 2013, o governo estadual divulgou a realização do Estudo de Impacto Ambiental (EIA) junto com um Plano Básico Ambiental para avaliar o melhor traçado dos 76,6 km da PR 405. Instituições ambientalistas propõem que a estrada possa ser melhorada seguindo as recomendações ambientais prescritas, com estudos específicos e adotando técnicas de impacto mínimo, considerando a dinâmica ambiental e social da região (AEN, 2016).

Porém, as opiniões ainda são divergentes entre a população local, que anseia melhores condições de transporte, mas teme a especulação imobiliária e a alteração do ambiente e do modo de vida local (MUNIZ, 2016). O problema afeta os residentes de maneira generalizada, mas pode-se salientar a ocorrência do conflito na sede do município de Guaraqueçaba, ao final da estrada, e as comunidades Cacatu, Tagaçaba, Serra Negra, Açungui, Potinga, Morato, Limoeiro e Vila Nova, que se distribuem ao longo dela.

TABELA 2 - POPULAÇÃO LOCAL E PAVIMENTAÇÃO DA PR 405

\begin{tabular}{l|l}
\hline $\begin{array}{l}\text { População } \\
\text { atingida }\end{array}$ & Agricultores familiares e população urbana. \\
\hline Comunidade(s) & Sede, Cacatu, Tagaçaba, Serra Negra, Açungui, Potinga, Morato, Limoeiro e Vila Nova. \\
\hline Tensões & $\begin{array}{l}\text { Alteração no modo de vida local, reconfiguração do uso e da ocupação do espaço, mudança nas } \\
\text { rotas de destino e meios de transporte. }\end{array}$ \\
\hline $\begin{array}{l}\text { Impactos } \\
\text { ambientais }\end{array}$ & Aumento da caça e da extração seletiva de madeira e de palmito. \\
\hline Referências & AEN (2016); CAMPOS (2013); CAMPOS (2014); MUNIZ (2016). \\
\hline
\end{tabular}

FONTE: adaptado de PAULA et al. (2016).

A PR 405 reconfigurou o uso e a ocupação do território e atualmente configura o conflito acerca de sua pavimentação. A questão da estrada envolve a necessidade iminente de melhoria da qualidade de vida das populações e as limitações necessárias para assegurar que ocorram impactos ambientais mínimos. Dessa maneira, estudiosos da área de conservação da natureza apontam que a pavimentação deveria ocorrer com o uso de tecnologias alternativas, entretanto, o caso não se restringe apenas ao encontro de soluções técnicas, mas a decisões de esferas políticas que envolvem interesses e relações não explícitas. 
Embora anterior à construção da PR 405, o estabelecimento dos latifundiários ${ }^{4}$ no território, favorecido pelos incentivos governamentais ${ }^{5}$ da década de 1970, foi impulsionado pela estrada. Segundo Souza (2010), com a construção da PR 405 ocorreu o aumento dos rebanhos de gado (anteriormente irrisórios) e a introdução de búfalos africanos, que apesar da adaptação não predominaram. Enfatiza ainda que com o investimento dos latifundiários na produção do palmito, os quais tinham recursos suficientes para fazer frente à demanda, despontou o conflito com os agricultores locais que viviam da extração.

Em relação à criação de búfalos na $\mathrm{AE}$, Cornetta (2005) afirma:

A ocupação e a expansão fundiária da bubalinocultura, por meio de regularização duvidosa da compra das terras ou grilos, acarretaram na concentração fundiária e na expropriação dos posseiros, moradores há muito do local. Isto ocorreu por meio de conflitos violentos que resultaram, em geral, no deslocamento espacial dos pequenos agricultores para terras menos férteis, com menor acesso aos recursos florestais, e até mesmo para as periferias de Antonina e Curitiba. Com a chegada dos fazendeiros "de fora", muitos posseiros sem perspectivas de trabalho e de terras passaram, também, a integrar a mão-de-obra assalariada na bubalinocultura. Além do impacto social, o ambiental também se faz presente neste processo, identificado no desmatamento, na compactação do solo, assoreamento e contaminação de cursos d'água (CORNETTA, 2005, p. 3).

Com isso, o conflito observado ${ }^{6}$ entre a população local e os latifundiários se dá em torno dos impactos ambientais decorrentes das atividades desse grupo social, como: compactação do solo por búfalos, supressão de APP e desvio de curso d'água para dessedentação dos animais, com consequente assoreamento de rios e introdução da Bracchiaria, espécie de gramínea exótica, em amplas extensões de pastagens, além da sobreposição de territórios devido à ausência de regularização fundiária.

\footnotetext{
${ }^{4}$ Miguel (1997 apud Teixeira, 2004) adota a expressão neolatifundiários para os grupos de empresas madeireiras e grupos industriais e comerciais que se instalaram em grandes propriedades destinadas à exploração dos recursos naturais ou à especulação. Ressalta-se que no presente artigo optou-se em utilizar o termo latifundiários.

${ }^{5}$ Particularmente, o Fundo de Investimento Setorial (FISET) de 1974 atraiu para o litoral norte do Paraná fazendeiros criadores de búfalos de Curitiba, São Paulo, Santa Catarina e Rio Grande do Sul (CORNETTA, 2005).

${ }^{6}$ Informação cedida durante visita às comunidades da AE, em setembro de 2016.
} 
TABELA 3 - POPULAÇÕES LOCAIS E LATIFUNDIÁRIOS

\begin{tabular}{l|l}
\hline $\begin{array}{l}\text { População } \\
\text { atingida }\end{array}$ & Agricultores familiares. \\
\hline Comunidade(s) & Comunidades rurais de Antonina e Guaraqueçaba. \\
\hline Tensões & $\begin{array}{l}\text { Sobreposição de território, reconfiguração do uso e da ocupação do espaço, ausência de } \\
\text { regularização fundiária. }\end{array}$ \\
\hline $\begin{array}{l}\text { Impactos } \\
\text { ambientais }\end{array}$ & $\begin{array}{l}\text { Compactação do solo por búfalos; supressão de APP para dessedentação dos animais; introdução } \\
\text { da Bracchiaria, espécie de gramínea exótica, em amplas extensões de pastagens; assoreamento dos } \\
\text { rios devido à supressão de APPs; desvio de curso d'água. }\end{array}$ \\
\hline Referências & CORNETTA (2005); SILVA (2012); SOUZA (2010). \\
\hline
\end{tabular}

FONTE: adaptado de PAULA et al. (2016).

Interessante retomar que tanto a usina quanto a pavimentação e os incentivos à criação de búfalos se encontram sob o contexto apontado por Acselrad (2004, p. 27), do período entre o pós-guerra e os anos oitenta, em que havia um modelo desenvolvimentista, com grandes projetos de apropriação do espaço que produziram impactos e efeitos de desestruturação de ecossistemas e afetaram populações ribeirinhas, pequenos agricultores, entre outros.

\section{Incompatibilidades no uso do território: os conflitos em torno do controle dos recursos comuns}

Em decorrência dos agravos ambientais causados pela exploração do território e sob pressão do movimento ambientalista brasileiro, que desponta na década de 1980, as UCs em Guaraqueçaba surgem como prática de ordenamento territorial com intuito de conter a utilização predatória dos recursos naturais e sob o argumento da necessidade de proteger o terceiro complexo lagunar-estuarino mais importante do mundo (FIOCRUZ, 2016).

A presença de UC indica uma vontade política de preservar bens ambientais, que pode ser compartilhada pela maioria dos atores sociais presentes no território. Ou pode significar justamente o oposto, gerando reações de amplos setores contrários à sua existência. Num momento histórico como o atual, no qual em 15 anos o Brasil mais do que duplicou a quantidade de suas áreas protegidas, esse embate entre tendências está posto no território e ocorre em uma escala muito mais ampla, na qual o território da UC está envolvido (MMA, 2015).

Na concepção de Little (2001), os conflitos socioambientais ocorrem mediante embates entre grupos sociais, com modos diferentes de se inter-relacionar com o ambiente social e natural. Por esse viés, os conflitos surgem das interações ecológicas entre os diferentes atores sociais e o meio biofísico. Segundo o autor, os conflitos em torno do controle dos recursos naturais, quando o homem 
define um uso para determinado elemento da natureza, têm três dimensões. A dimensão política está relacionada com a distribuição dos recursos; a dimensão social se refere a disputas sobre o acesso a recursos naturais; e a jurídica é a disputa formal pelo recurso (LITTLE, 2001).

As tensões entre os objetivos das UCs e as práticas produtivas e culturais tradicionalmente realizadas pela população local, como a pesca e a agricultura, tratam-se de um conflito entendido como de dimensão política, pois a esfera de poder e decisão em que se institui uma UC não perpassa, muitas vezes, pelo desejo de populações locais, sobrepondo e prevalecendo interesses não comuns. A síntese desse conflito, na AE, está alocada na Tabela 4.

TABELA 4 - POPULAÇÕES LOCAIS E UC

\begin{tabular}{l|l}
\hline $\begin{array}{l}\text { População } \\
\text { atingida }\end{array}$ & Agricultores familiares, caiçaras, quilombolas pescadores artesanais e indígenas. \\
\hline Comunidade(s) & $\begin{array}{l}\text { Acampamento José Lutzenberger, Comunidades Remanescentes Quilombolas de Batuva e Rio } \\
\text { Verde, Potinga, Engenho Velho, Guapicum, Massarapuã, Tromomô, Almeida, Tibicanga. }\end{array}$ \\
\hline Tensões & $\begin{array}{l}\text { Sobreposição de territórios, alteração no regime tradicional de uso e ocupação do território, } \\
\text { participação social de baixa efetividade. }\end{array}$ \\
\hline $\begin{array}{l}\text { Impactos } \\
\text { ambientais }\end{array}$ & Caça, pesca e extrativismo predatórios. \\
\hline Referências & $\begin{array}{l}\text { ARANTES (2016); CORNETTA (2005); LOURENÇO et al. (2012); SCHWARTZMAN; } \\
\text { SIBUYA (2013); TEIXEIRA; LIMONT (2007). }\end{array}$ \\
\hline
\end{tabular}

FONTE: adaptado de PAULA et al. (2016).

Dos conflitos socioambientais levantados na AE dois estão em disputa formal pelo recurso, embora também apresentem viés político e social em suas gêneses. O primeiro diz respeito à sobreposição de territórios, entre a REBIO Bom Jesus e Aldeia Indígena Guarani Kuaray Haxa, o qual tem como tensão a sobreposição de territórios. De um lado, a preocupação com os impactos que a presença humana possa gerar na unidade, cuja classe de uso é das mais restritivas; de outro, o direito dos povos originários à regularização de territórios tradicionalmente ocupados.

Às margens da PR 405, na divisa dos municípios de Antonina e Guaraqueçaba, encontra-se a Aldeia Guarani Kuaray Haxa. Os indígenas são migrantes da Terra Indígena (TI) Mangueirinha, no interior do Paraná, e conforme informações da Fundação Nacional do Índio (FUNAI), o grupo deixou sua terra de origem em razão de conflitos com índios da etnia Kaingang que, juntamente com os da Guarani, ocupam a referida TI. Após terem abandonado a TI, esse grupo tentou se estabelecer, sem sucesso, em outras terras indígenas, até se fixarem em definitivo na área onde veio a ser criada a REBIO Bom Jesus, em 2012 (FIOCRUZ, 2016). 
Com o apoio do Ministério Público Federal (MPF) e da FUNAI, os indígenas conseguiram que a Justiça Federal decidisse, em novembro de 2014, pela permanência da Aldeia Kuaray Haxa na área. O Tribunal Regional Federal da $4^{\mathrm{a}}$ Região (TRF4) entendeu que a presença da comunidade não traria prejuízo à UC, entretanto a sentença ainda não é definitiva. O resumo desse conflito é exposto na tabela a seguir:

TABELA 5 - ALDEIA INDÍGENA GUARANI KUARAY HAXA E REBIO BOM JESUS

\begin{tabular}{l|l}
\hline $\begin{array}{l}\text { População } \\
\text { atingida }\end{array}$ & Indígenas. \\
\hline Comunidade(s) & Aldeia Indígena Guarani Kuaray Haxa. \\
\hline Tensões & $\begin{array}{l}\text { Alteração no regime tradicional de uso e ocupação do território; ausência/irregularidade na } \\
\text { demarcação de território tradicional. }\end{array}$ \\
\hline $\begin{array}{l}\text { Impactos } \\
\text { ambientais }\end{array}$ & $\begin{array}{l}\text { Falta de saneamento básico; invasão/dano à área protegida ou unidade de conservação; } \\
\text { extrativismo ilegal de palmito. }\end{array}$ \\
\hline Referências & $\begin{array}{l}\text { BRASIL (2014); BRASIL (2014); FIOCRUZ (2016); ROCHA (2015); SCHWARTZMAN e } \\
\text { SIBUYA (2013); SILVA (2012). }\end{array}$ \\
\hline
\end{tabular}

FONTE: Adaptado de PAULA et al. (2016).

O segundo conflito em dimensão jurídica é uma ação civil pública movida pelo Movimento dos Pescadores Artesanais do Paraná (MOPEAR) ao ICMBio no tocante à elaboração do Plano de Manejo (PM) do Parque Nacional de Superagüi (PNS). Em dezembro de 2013, na comunidade da Barra do Superagüi, o MOPEAR promoveu audiência pública para tratar da política de criação de UC de Proteção Integral. Estiveram presentes cerca de 200 pessoas, entre pescadores artesanais e representantes de instituições públicas federais e estaduais. Dois dos fatores que desencadearam a audiência foram: a cobrança pela elaboração do PM do PNS com participação das comunidades e a recente criação por meio de lei federal do Parque Nacional Marinho da Ilha de Currais.

Em maio de 2015, a ação civil pública foi movida com o apoio da Defensorias Públicas do Estado (DPPR) e da União (DPU) e uma decisão liminar da Justiça Federal obrigou o ICMBio a disponibilizar às instituições e aos pescadores tradicionais os documentos e estudos do PM do PNS e a garantir a efetiva participação do MOPEAR na elaboração do referido Plano, bem como observar as diretrizes da Convenção 169 da Organização Internacional do Trabalho (OIT) de 2004. A súmula do conflito é apresentada na Tabela 6. 
DO PARANÁ (MOPEAR)

\begin{tabular}{l|l}
\hline $\begin{array}{l}\text { População } \\
\text { atingida }\end{array}$ & Pescadores artesanais. \\
\hline Comunidade(s) & $\begin{array}{l}\text { Saco do Morro, Bertioga, Sebuí, Poruquara, Barra do Superagüi, Vila das Peças, Medeiros }{ }^{7}, \text { Vila } \\
\text { Mariana, Taquanduva, Almeida e Cerco Grande. }\end{array}$ \\
\hline Tensões & $\begin{array}{l}\text { Sobreposição de territórios, alteração no regime tradicional de uso e ocupação do território, } \\
\text { participação social de baixa efetividade. }\end{array}$ \\
\hline $\begin{array}{l}\text { Impactos } \\
\text { ambientais }\end{array}$ & Pesca ou caça predatória. \\
\hline Referências & AZEVEDO (2016); DPPR (2015); DUARTE (2013); FIOCRUZ (2016). \\
\hline
\end{tabular}

FONTE: Adaptado de PAULA et al. (2016).

A legislação ambiental restringe práticas da população local mesmo antes da promulgação do SNUC. O direito ambiental brasileiro, através do Código Florestal, já disciplinava o uso dos recursos naturais desde 1965, e ganha reforço com a Constituição Federal de 1988 e a Lei de Crimes Ambientais uma década depois. Com todo esse arcabouço jurídico, as comunidades da AE se veem obrigadas a abster-se de algumas de suas práticas tradicionais de produção e buscar alternativas de sobrevivência que não as coloquem em desacordo com a lei.

Paralelo ao cumprimento da legislação está a fiscalização ambiental, um procedimento administrativo adotado pelo Estado para apuração de danos lesivos ao meio ambiente e para realização de investigações ambientais baseada em ações preventivas e repressivas. No Paraná, a

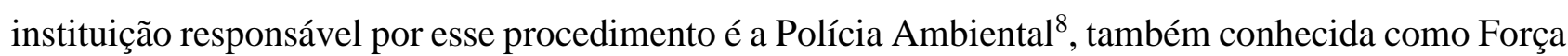
Verde.

Embora a repressão às ameaças ao meio ambiente esteja entre as competências da Polícia Ambiental $^{9}$, o que torna as ações de fiscalização um conflito, é a abordagem praticada por essa instituição. De acordo com Arantes (2016), a fiscalização ambiental, em especial feita pela Força

\footnotetext{
${ }^{7}$ Optou-se por representar as comunidades de Medeiros de Baixo e de Cima no mapa.

${ }^{8}$ Unidade especializada da Polícia Militar do Paraná encarregada de monitorar e coibir os crimes ambientais cometidos nas áreas sob jurisdição do executivo paranaense.

${ }^{9}$ Entre as atribuições da polícia ambiental estão: executar o policiamento ostensivo de forma preventiva ou repressiva, com a finalidade de coibir e dissuadir ações que representem ameaças ou depredações da natureza; zelar pelo cumprimento da legislação ambiental de defesa da flora e fauna silvestre observando os dispositivos das leis federais e estaduais, bem como as portarias e resoluções em vigor; autuar os infratores ambientais, instrumentalizando, ainda, o Ministério Público nas ações civis de recuperação dos danos provocados contra a natureza; realizar prisões de infratores, que sejam flagrados no cometimento de crimes ambientais e encaminhá-los à presença da autoridade policial, para a lavratura do auto de prisão em flagrante delito e/ou inquérito policial, bem como prestar as devidas informações que, posteriormente, se façam necessárias; orientar a população acerca da legislação ambiental e da importância do seu cumprimento, relacionando-a com a necessidade de criação, conservação e proteção das Unidades de Conservação (PMPR, 2016).
} 
Verde, é bastante criticada pelos moradores entrevistados em sua pesquisa, que a entendem como rude, truculenta e rígida. Os relatos ${ }^{10}$ dos moradores do acampamento José Lutzenberger, da Comunidade Remanescente de Quilombo de Batuva e da comunidade de pesca artesanal de Almeida alertam para a necessidade de diálogo como forma de combater esse tipo de fiscalização, que não considera a compatibilidade do uso tradicional do território com a conservação da natureza. Como coloca Silva (2012), o conflito apresentado pelos moradores está na inquietação diante de uma legislação ambiental que desorganiza suas práticas culturais tradicionais, vitais para a reprodução social da sua vida e trabalho.

Na concepção de Little (2001), esse conflito ambiental se classifica como de dimensão social, pois as populações locais encontram-se cerceadas de acesso aos recursos naturais indispensáveis à sobrevivência. A sinopse desse conflito está disposta na Tabela 7.

TABELA 7 - POPULAÇÕES LOCAIS E FISCALIZAÇÃO AMBIENTAL

\begin{tabular}{l|l}
\hline $\begin{array}{l}\text { População } \\
\text { atingida }\end{array}$ & Pescadores artesanais, caiçaras e quilombolas. \\
\hline Comunidade(s) & Acampamento José Lutzenberger; Comunidade Remanescente Quilombola de Batuva; Almeida. \\
\hline Tensões & $\begin{array}{l}\text { Incompatibilidade no uso tradicional do território pelas populações com a legislação ambiental e } \\
\text { improbidade na abordagem da Força Verde (Polícia Ambiental) em ações de fiscalização. }\end{array}$ \\
\hline $\begin{array}{l}\text { Impactos } \\
\text { ambientais }\end{array}$ & Agravo ou criação de impactos em virtude da fiscalização. \\
\hline Referências & ARANTES (2016); BAZZO (2010); SILVA (2012). \\
\hline
\end{tabular}

FONTE: Adaptado de PAULA et al. (2016).

O último conflito exposto neste artigo, conforme a presente análise, pode se encaixar na dimensão política (LITTLE, 2001), pois os manguezais utilizados tradicionalmente por parte de comunidades pesqueiras do município de Guaraqueçaba foram especificamente protegidos pela criação da ESEC de Guaraqueçaba em 1982 e amplamente protegidos pela Resolução CONAMA 302/2002, que conceituou expressamente os manguezais como Áreas de Preservação Permanente (APP).

O ecossistema predominante na ESEC de Guaraqueçaba são os manguezais, um ecossistema que com frequência é altamente produtivo, servindo de abrigo para inúmeras espécies e que providenciam renda à população da região, principalmente através da captura de caranguejo-uçá e ostra (SILVA, 2013). Dada a importância ecológica desse ecossistema, a captura do caranguejo é

\footnotetext{
${ }^{10}$ Informação cedida durante atividade de campo em visita às comunidades da AE, em setembro de 2016.
} 
orientada por legislações ambientais federais e estaduais, o que tem gerado tensões e conflitos entre os órgãos responsáveis pelo controle e fiscalização ambiental e pescadores das vilas usuárias desses recursos nos manguezais (ARANTES, 2016).

Além das funções ecológicas, diversos produtos dos manguezais são explorados diretamente pelas comunidades costeiras, especialmente recursos pesqueiros, como ostras e caranguejos, mas também a madeira e extratos vegetais (FARACO, 2012). Nas vilas pesqueiras do Complexo Estuarino de Paranaguá, a extração de madeira procedente dos manguezais atualmente é rara, mas quando ocorre, é usada para varas de amarrar rede e embarcação de pesca, construção de ranchos de embarcações e elevação da base das casas (SANTOS, 2013).

A Tabela 8 aloca a síntese do conflito exposto acima.

TABELA 8 - PESCADORES ARTESANAIS E ESEC DE GUARAQUEÇABA

\begin{tabular}{l|l}
\hline População atingida & Pescadores artesanais. \\
\hline Comunidade(s) & Almeida, Engenho Velho, Guapicum, Ilha Rasa, Massarapuã, Medeiros, Tibicanga, Tromomô. \\
\hline Tensões & $\begin{array}{l}\text { Incompatibilidade no uso tradicional do território pelas populações com a legislação ambiental e } \\
\text { restrição a técnicas de pesca. }\end{array}$ \\
\hline $\begin{array}{l}\text { Impactos } \\
\text { ambientais }\end{array}$ & Dificuldade de integrar as populações locais aos objetivos da conservação da natureza. \\
\hline Referências & ARANTES (2016); FARACO (2012); SILVA (2013). \\
\hline
\end{tabular}

FONTE: Adaptado de PAULA et al. (2016).

\section{Espacialização dos conflitos e alguns desdobramentos}

Da observação do mapa dos conflitos (Erro! Fonte de referência não encontrada.) percebese que aqueles decorrentes da fiscalização ambiental ocorrem nas comunidades de pescadores artesanais, quilombolas e no acampamento. No sentido de compreensão e tratamento do conflito é importante compreender quais práticas são restringidas por quais leis e normas ambientais, já que são recorrentes desentendimentos sobre quem são os responsáveis por quais atribuições, sejam da polícia ambiental, dos órgãos ambientais, das ONGs, prefeituras, Estado, entre outros. Nesse sentido, a participação das comunidades nos conselhos gestores é de suma importância, pois possibilita o diálogo e esclarece entraves. Paula et al. (no prelo) demonstra que as unidades que possuem conselho gestor têm realizado apenas uma reunião anual, sendo justamente destacada a realização conjunta de reuniões dos conselhos da APA e ESEC, afim de viabilizá-las. 


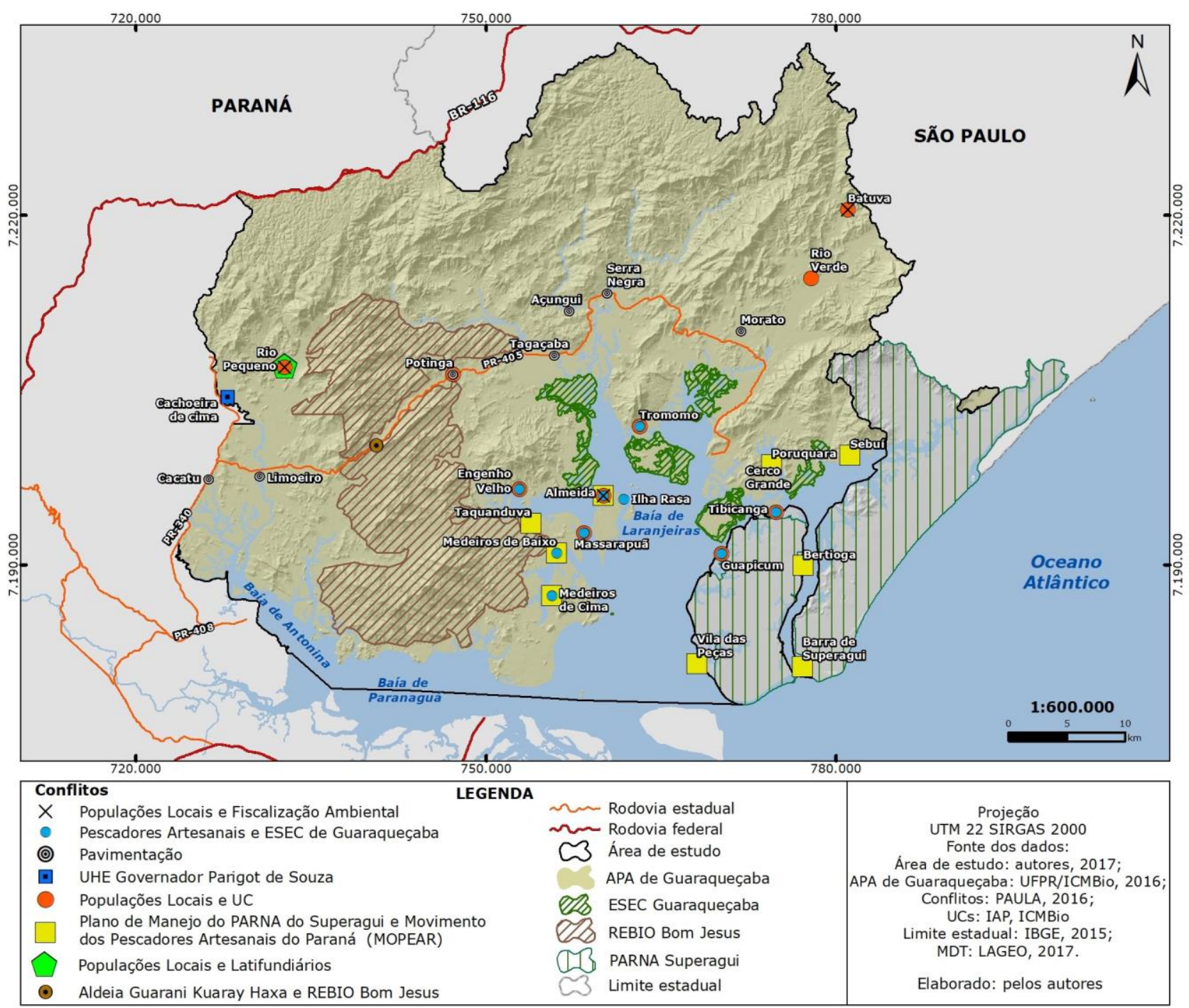

FIGURA 2 - DISTRIBUIÇÃO DOS CONFLITOS AMBIENTAIS NA ÁREA DE ESTUDO FONTE: Os Autores.

Nota-se ainda que as comunidades pontuadas pelos conflitos que envolvem as populações locais e as UC são, com exceção de Tibicanga e Guapicum, recobertas apenas pela APA, ou seja, os níveis de restrição são de unidades de uso sustentável e não de proteção integral, o que demanda prontamente novos esforços de investigação para se compreender como se dão essas práticas tradicionais que não condizem sequer com o uso sustentável e de que maneira é possível equipará-las a ele.

O conflito "PM do PARNA de Superagüi e MOPEAR" é pontuado em diversas comunidades fora do perímetro do Parque em função da tensão gerada pelo conflito em outras localidades e também pelo alcance que o MOPEAR passou a ter nas comunidades. É preciso compreender de que forma as 
comunidades têm se relacionado com o movimento, de que maneiras e quais as pautas, discernindo quais estão engajadas no caso do Plano de Manejo de Superagüi e quais se ocupam de causas outras.

Cabe ainda destacar que a não espacialização de um conflito não significa a não existência dele, assim como cabe reiterar que esta é uma primeira organização dos dados, que precisa ser complementada, mas que objetiva contribuir para a percepção da distribuição e características dos conflitos. Da mesma maneira algumas comunidades são citadas como foco de determinados conflitos nas Tabelas Sínteses, porém não estão pontuadas na Figura 2 por não ter sido possível o georreferenciamento de todas as comunidades da AE.

A análise de conflitos envolve a identificação do seu contexto ambiental, geográfico e historicamente (LITTLE, 2001). É possível caracterizá-lo por um conjunto de elementos, destacando-se: natureza, atores sociais envolvidos, campo específico, o objeto da disputa, dinâmica de evolução, existência de mediadores ou observadores. A natureza pode ser econômica, política, social, ambiental, cultural, geracional, geográfica, dentre outras. Os atores articulam-se ou se opõem e nem sempre os seus discursos são coerentes. O objeto pode ser material ou simbólico, real ou irreal, e envolve várias ideias, status e posição de poder. A dinâmica é o modo que se manifesta e evolui o conflito. Os mediadores ou observadores são os que presenciam o conflito, defendendo ou não uma posição (NASCIMENTO, 2001).

A partir das percepções, ou seja, do conhecimento e entendimento dos atores sobre as questões ambientais, é possível desenvolver estratégias de gestão, de forma a reduzir os impactos e manejar os conflitos ambientais. Os conflitos são dinâmicos, podendo se intensificar com a incorporação de novos assuntos e atores, ou diminuir, a partir de novos contextos e boa mediação (VARGAS, 2007).

No caso da ESEC, a gestão tem procurado mediar a situação de irregularidade dos pescadores diante das leis ambientais, através de um termo de compromisso. Além disso, tem auxiliado os pescadores em um pedido judicial visando à alteração da legislação estadual ${ }^{11}$ que rege a captura do caranguejo-uçá no território, permitindo o uso da técnica do laço/lacinho. Essa técnica é muito utilizada na região, mas nem todas as vilas pesqueiras a utilizam por não considerarem benéfica para o pescador e para o meio ambiente (ARANTES, 2016). O conflito relacionado à ESEC reitera essas tensões entre os objetivos conservacionistas e as práticas produtivas tradicionalmente realizadas pela população local. Porém, é um bom exemplo em que a mediação realizada pelo ICMBio e o diálogo entre os diferentes atores tem resultado na gestão compartilhada dos recursos naturais.

\footnotetext{
${ }^{11}$ A portaria IAP $\mathrm{n}^{\circ}$ 180/2002 não permite a técnica do lacinho devido aos resíduos gerados pelo material que compõe o artefato e que podem ser deixados no mangue. No entanto, a portaria não menciona o período de reprodução da espécie, que ocorre justamente nos meses de dezembro e janeiro, quando está liberada a captura (IAP, 2002).
} 
Outra iniciativa que merece destaque é o trabalho agroflorestal desenvolvido pelas 20 famílias do Acampamento José Lutzenberger do MST. O acampamento ocupa parte APA de Guaraqueçaba, e desde 2003 concilia a produção de alimentos livres de agrotóxicos com a recuperação da Mata Atlântica. Por isso, a comunidade foi contemplada no prêmio Juliana Santilli, na categoria ampliação e conservação da agrobiodiversidade.

\section{Considerações Finais}

Percebe-se que os conflitos ocorrem tanto entre as populações e as atividades causadoras de impactos ambientais quanto entre elas e aspectos decorrentes de normativas ambientais. Essa constatação demanda uma linha de mediação de conflitos que concilie as práticas culturais das populações com as normativas ambientais para que, em consonância, faça frente às iniciativas geradoras de impactos.

Embora haja algum reconhecimento de que agricultores familiares e povos e comunidades tradicionais sejam importantes agentes na conservação da natureza, estes precisam contar com um aparato jurídico, como a Constituição Federal de 1988, a Convenção nº 169 da Organização Internacional do Trabalho de 2004 e a Política Nacional de Desenvolvimento dos Povos e Comunidades Tradicionais de 2007, para a superação dos diferentes interesses que levam aos conflitos, especialmente na dimensão jurídica. É importante que essas estratégias de reconhecimento sejam adotadas de modo que os direitos sejam garantidos.

Por outro lado, o nível de implementação das UC na região é baixo (PAULA et al., no prelo), reflexo de equipes insuficientes, estrutura física limitada, poucos conselhos gestores, ausência e/ou baixa aplicação dos planos de manejo e outros instrumentos de planejamento, colocando em cheque a eficiência da gestão das unidades e a capacidade de tratamento de conflitos por parte dos órgãos.

Assim, enfatiza-se a preocupação do presente artigo em reunir informações acerca do tema e retratar um panorama dos conflitos ambientais observados na $\mathrm{AE}$, ressaltando que os resultados aqui apresentados não esgotam a discussão, pelo contrário, estabelecem uma base para outras investigações que possam contribuir para o encaminhamento de resoluções para o desenvolvimento desse campo de conhecimento. 


\section{Referências}

AGÊNCIA ESTADUAL DE NOTÍCIAS (AEN). Richa autoriza estudo para pavimentação da estrada de acesso a Guaraqueçaba. Curitiba, jan. 2013. Disponível em: 〈goo.gl/aVqWbV〉. Acesso em: 30 out. 2016.

ARANTES, A. C. A dinâmica atual do conflito entre uso e conservação de recursos pesqueiros na Estação Ecológica de Guaraqueçaba, Paraná. 2016. Dissertação (Mestrado em Meio Ambiente e Desenvolvimento) - da Universidade Federal do Paraná, Curitiba, 2016.

BRASIL. Constituição: República Federativa do Brasil (promulgada em 5 out. 1988). Brasília, Senado Federal, 1988.

BRASIL. Lei $\mathrm{n}^{\circ}$ 11.428, de 11 de dezembro de 2006. Dispõe sobre a utilização e proteção da vegetação nativa do bioma Mata Atlântica, e dá outras providências. Diário Oficial [da] República

Federativa do Brasil, Brasília, DF, 26 dez. 2006. Disponível em: < http://www.planalto.gov.br/ccivil_03/_ato2004-2006/2006/lei/111428.htm>. Acesso em: 10 mar. 2017.

CAMPOS, L. A. de P.; KOMARCHESKI, Rosilene; SULZBACH, M. T. Conflitos socioambientais em Guaraqueçaba-PR: o caso da rodovia da banana. In: Anais da II Jornada de Questão Agrária e Desenvolvimento: projetos sociais e políticas públicas em disputa. Curitiba: UFPR, 2013. v. 1.

CORNETTA, A. A Mata Atlântica privada: conflitos agrários na APA de Guaraqueçaba - PR. Anais. III Simpósio Nacional de Geografia Agrária - II Simpósio Internacional de Geografia Agrária. Jornada Ariovaldo Umbelino de Oliveira. Presidente Prudente - SP, 2005.

FARACO, L. F. D. Vulnerabilidade de pescadores paranaenses às mudanças climáticas e os fatores que influenciam suas estratégias de adaptação. 2012. $261 \mathrm{f}$. Tese (Doutorado em Meio Ambiente e Desenvolvimento) - Universidade Federal do Paraná, Curitiba, 2012.

LAVILLE, C.; DIONE, J. A construção do saber: Manual de Metodologia da Pesquisa em Ciências Humanas. Porto Alegre: Artemed; Belo Horizonte: Editora UFMG, 1999.

FUNDAÇÃO OSWALDO CRUZ (FIOCRUZ). Mapa de conflitos envolvendo injustiça ambiental e saúde no Brasil. Disponível em: <http://www.conflitoambiental.icict.fiocruz.br/index.php?pag=ficha\&cod=38>. Acesso em: 09 out. 2016.

MINISTÉRIO DO MEIO AMBIENTE (MMA). Ministério do Meio Ambiente, Secretaria de Articulação Institucional e Cidadania Ambiental. A Unidade de Conservação e o Território: reconhecendo o contexto socioambiental e geopolítico. Brasília: MMA, 2015. (Série Educação Ambiental e Comunicação em Unidades de Conservação).

MINISTÉRIO PÚBLICO DO PARANÁ (MPPR). Procedimento administrativo ${ }^{\circ}$ 0006.13.000217-0, 2013.

MUNIZ, J. C. PR 405 - A velha e esburacada estrada. Campanha de pavimentação, agora com cara e força nova. Guaraqueçaba, 15 fev. 2011. Disponível em: <http://informativo- 
nossopixirum.blogspot.com.br/2011/02/pr-405-velha-e-esburacada-estrada.html>. Acesso em: 15 nov. 2016.

ORGANIZAÇÃO INTERNACIONAL DO TRABALHO (OIT). Convenção no 169 sobre povos indígenas e tribais e Resolução referente à ação da OIT. Brasília: OIT, 2011. Disponível em: <http://portal.iphan.gov.br/baixaFcdAnexo.do?id=3764>. Acesso em: 07 jan. 2015.

PAUlA, E. V. et al. Diagnóstico de subsídio ao Plano de Manejo da APA de Guaraqueçaba, ESEC de Guaraqueçaba e REBIO Bom Jesus. 2016

PAULA, E. V. Análise da produção de sedimentos na área de drenagem da baía de Antonina/PR: Uma abordagem geopedológica. 2010. 220 f. Tese (Doutorado em Geografia) Universidade Federal do Paraná, Curitiba, 2010.

PAULA, E. V.; PIGOSSO, A. M. B.; WROBLEWSKI, C. A. Unidades de Conservação no

Litoral do Paraná: evolução territorial e grau de implementação. In: SULZBACH, M.;

QUADROS, J.; ARCHANJO, D. (Orgs.). Litoral do Paraná: Território e perspectivas: dimensões de desenvolvimento. 1. ed. Curitiba: Autografia, 2018. v. 1. 423p.

SANTOS, N. M. dos. Os manguezais do complexo estuarino de Paranaguá: variações interdecadais, distribuição da biomassa aérea e formas de uso da madeira. 2013. 94 f. Dissertação (Mestrado em Sistemas Costeiros e Oceânicos) - Universidade Federal do Paraná, Pontal do Paraná, 2013.

POLÍCIA MILITAR DO PARANÁ (PMPR). Histórico do batalhão da Polícia Ambiental. Disponível em: <http://www.pmpr.pr.gov.br/modules/conteudo/conteudo.php?conteudo=37>. Acesso em: 15 dez. 2016.

SCHMINK, M.; REDFORD, K. H.; PADOCH, C. Traditional peoples and the biosphere: framing the issues and defining the terms. In: REDFORD, K. H.; PADOCH, C. (Orgs.). Conservation of neotropical forests: working from traditional resource use. New York: Columbia University Press, 1992. p. 3-10.

SILVA, J. O. Os usos dos manguezais nas unidades de conservação de Guaraqueçaba - PR: dinâmicas socioambientais. 2013. 203 f. Dissertação (Mestrado em Meio Ambiente e Desenvolvimento) - Universidade Federal do Paraná, Curitiba, 2013.

SILVA, L. R. O. da. Conflitos socioambientais no litoral paranaense: a relação homem e natureza no bioma Mata Atlântica. Anais do XI Encontro Nacional de História Oral: Memória Democracia e Justiça, Simpósio Temático História, Natureza, Cultura e Oralidade, UFRJ. Rio de Janeiro, 11 de julho de 2012.

SOUZA, M. R. Paisagem cultural: patrimônio histórico de Guaraqueçaba/PR. Revista Geoingá, Maringá, v. 2, n. 2, p. 102-123, 2010.

THIOLLENT, M. Metodologia da pesquisa-ação. 11. Ed. São Paulo: Cortez, 2002.

VARGAS, G. M. Território. In: FERRARO JUNIOR, L. A. Encontros e caminhos: formação de educadoras(es) ambientais e coletivos educadores. Brasília: MMA, 2014. (Volume 3). Disponível 
em: <http://pt.scribd.com/doc/228157241/Livro-Encontros--e-Caminhos-Vol-3\#scribd>. Acesso em: fev. 2015.

ZHOURI, A.; LASCHEFSKI, K. (Orgs.). Desenvolvimento e conflitos ambientais. Belo Horizonte: Editora UFMG, 2010.

Artigo recebido em 31/03/2018. Aceito para publicação em 20/07/2018. 